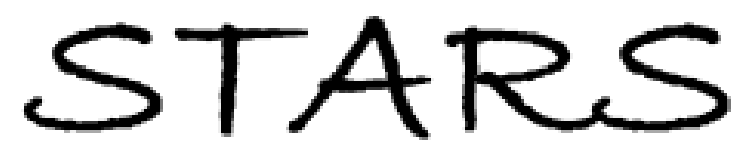

University of Central Florida

STARS

$1-1-2011$

\title{
Airtight container for the transfer of atmosphere-sensitive materials into vacuum-operated characterization instruments
}

Romain M. Gaume

University of Central Florida

Lydia-Marie Joubert

Find similar works at: https://stars.library.ucf.edu/facultybib2010

University of Central Florida Libraries http://library.ucf.edu

This Article is brought to you for free and open access by the Faculty Bibliography at STARS. It has been accepted for inclusion in Faculty Bibliography 2010 s by an authorized administrator of STARS. For more information, please contact STARS@ucf.edu.

\section{Recommended Citation}

Gaume, Romain M. and Joubert, Lydia-Marie, "Airtight container for the transfer of atmosphere-sensitive materials into vacuum-operated characterization instruments" (2011). Faculty Bibliography 2010 s. 1315. https://stars.library.ucf.edu/facultybib2010/1315

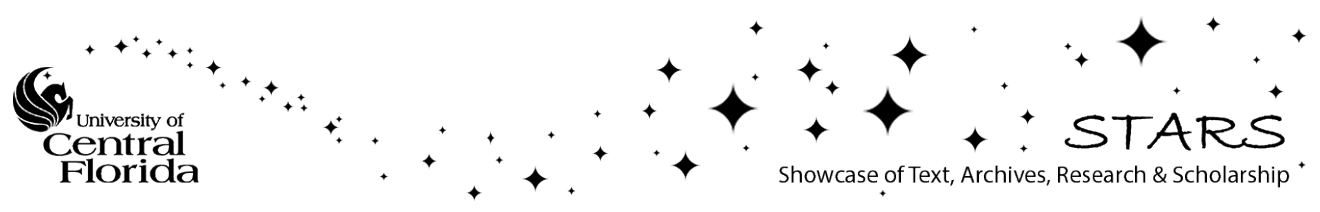




\section{Airtight container for the transfer of atmosphere-sensitive materials into vacuum- operated characterization instruments}

Romain M. Gaume, and Lydia-Marie Joubert

Citation: Review of Scientific Instruments 82, 123705 (2011); doi: 10.1063/1.3669784

View online: https://doi.org/10.1063/1.3669784

View Table of Contents: http://aip.scitation.org/toc/rsi/82/12

Published by the American Institute of Physics

\section{Articles you may be interested in}

Elastic airtight container for the compaction of air-sensitive materials

Review of Scientific Instruments 87, 063908 (2016); 10.1063/1.4954925

Low-profile self-sealing sample transfer flexure box

Review of Scientific Instruments 88, 083705 (2017); 10.1063/1.4997952

Air-lock system for the transfer of reactive samples to the Philips EM 300 S electron microscope

Review of Scientific Instruments 49, 101 (1978); 10.1063/1.1135236

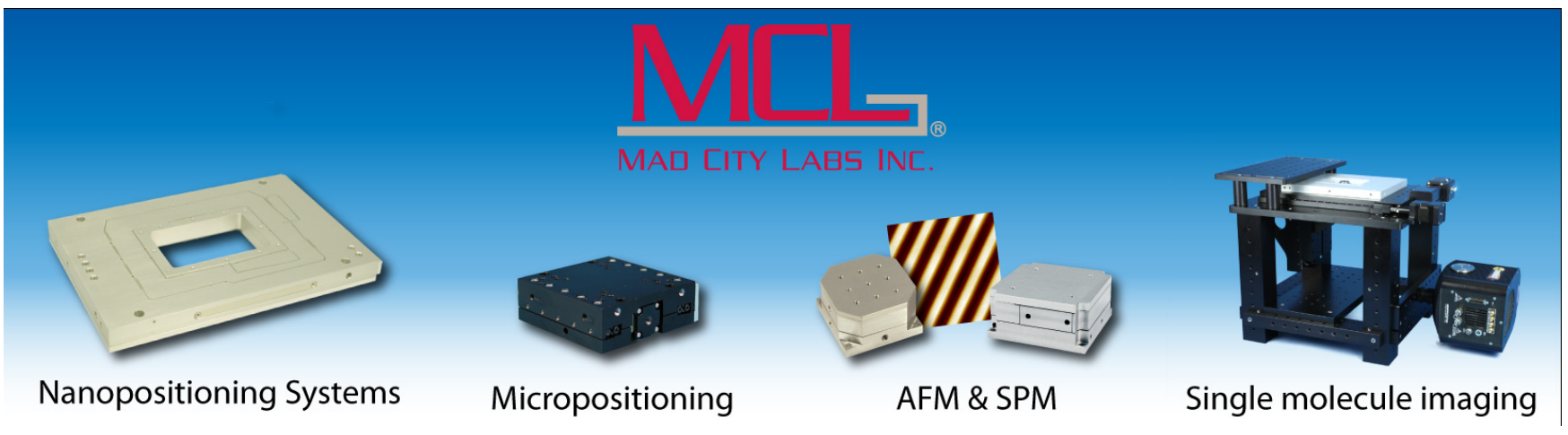




\title{
Airtight container for the transfer of atmosphere-sensitive materials into vacuum-operated characterization instruments
}

\author{
Romain M. Gaume ${ }^{1, \text { a) }}$ and Lydia-Marie Joubert ${ }^{2}$ \\ ${ }^{1}$ CREOL, the College of Optics and Photonics, University of Central Florida, Orlando, \\ Florida 32816-2700, USA \\ ${ }^{2}$ Cell Sciences Imaging Facility, Beckman Center, Stanford University, Stanford, California 94305, USA
}

(Received 20 July 2011; accepted 26 November 2011; published online 14 December 2011)

\begin{abstract}
This paper describes the design and operation of a simple airtight container devised to facilitate the transfer of atmosphere-sensitive samples from a glovebox to the vacuum chamber of an analytical instrument such as a scanning electron microscope. The use of this device for characterizing the microstructure of highly hygroscopic strontium iodide ceramics by scanning electron microscopy is illustrated as an application example. (C) 2011 American Institute of Physics. [doi:10.1063/1.3669784]
\end{abstract}

\section{INTRODUCTION}

Material characterization techniques such as electron microscopies, microprobes, x-ray photoelectron spectrometry or secondary ion mass spectrometry are few of the numerous techniques that have become integral to material science and biological studies. ${ }^{1}$ As a result, various methods have been developed for preparing and handling the most diverse materials. ${ }^{2}$ The characterization of atmospheresensitive materials, such as hygroscopic and pyrophoric materials, requires, however, special precautions to prevent air exposure during sample transfer from a preparation facility to such characterization instruments. The result of atmospheric exposure can indeed lead to rapid and significant damage of sample surfaces, degrading the very features of interest. The few methods that have been described in the literature to circumvent this issue make use of elaborate mechanically operated air-lock systems. ${ }^{3,4}$ The present article describes a simple device, which has been developed to transfer atmosphere-sensitive samples from a preparation facility, such as a glovebox, to a scanning electron microscope. This transfer is performed under dry inert gas at ambient temperature and pressure, and is illustrated here on an example.

\section{CONCEPT AND DESIGN}

The airtight container consists of a metallic canister covered with a disposable elastic rubber membrane. The membrane is held in place under very slight unidirectional tension using an O-ring, a metallic annular clamp, and two metallic braces (Figures 1 and 2). Before the elastic membrane is mounted, the atmosphere-sensitive sample is glued inside the container on a sample holder with an electrically conductive paste or a piece of carbon tape. All these various parts are easily assembled in a glovebox filled with an adequate inert atmosphere at ambient pressure. Once hermetically sealed, the container is taken out of the glovebox and transferred to the vacuum chamber of a characterization instrument. During

a) Author to whom correspondence should be addressed. Electronic mail: gaume@ucf.edu. the evacuation of the vacuum chamber, the membrane inflates due to the negative pressure difference that develops across it until it touches a sharp metallic tip, mounted on the inner side of the membrane clamp. This causes the elastic membrane to pop wide-open, exposing the sample to vacuum and to the instrument. The proximity of this sharp tip with the rest surface of the membrane guarantees that little elastic energy is stored in the film before it ruptures and that it does not fragment into loose debris, which might potentially damage the vacuum components of the instrument. The volume of the container must be kept reasonably small to limit the pressure burst in the vacuum chamber after the rupture of the membrane. It is also preferable to heat up the container and the membrane to about $100^{\circ} \mathrm{C}$ before its use so as to eliminate adsorbed water. Figure 1 shows the airtight container in cross section at ambient pressure and under increasing levels of vacuum until the membrane ruptures. A centering pin, underneath the container maintains the device in position on the sample stage of the instrument (Figure 2).

\section{MEMBRANE CHARACTERISTICS}

\section{A. Elastic and rupture properties}

The membrane material should be chosen for its highly elastic properties and its ability to inflate and reach the rupture needle under a differential pressure of one atmosphere. The elastomer should also have relatively high tensile strength to tear easily. ${ }^{5,6}$ At a given temperature and depending on the nature of the elastomer and the distribution of stress, rupture can either propagate as a single crack, or branch out of multiple and concomitant nucleation sites to produce torn fragments. The latter situation should naturally be avoided at all cost as loose membrane debris could potentially damage the instrument or obstruct surface features during further analysis. The present device has been specifically designed to meet the conditions for single crack propagation and where a single nucleation site is promoted by puncture, the elastomer is not too brittle, the strain-rate during the crack opening is small and the tension of the membrane is anisotropic. $^{7}$ 

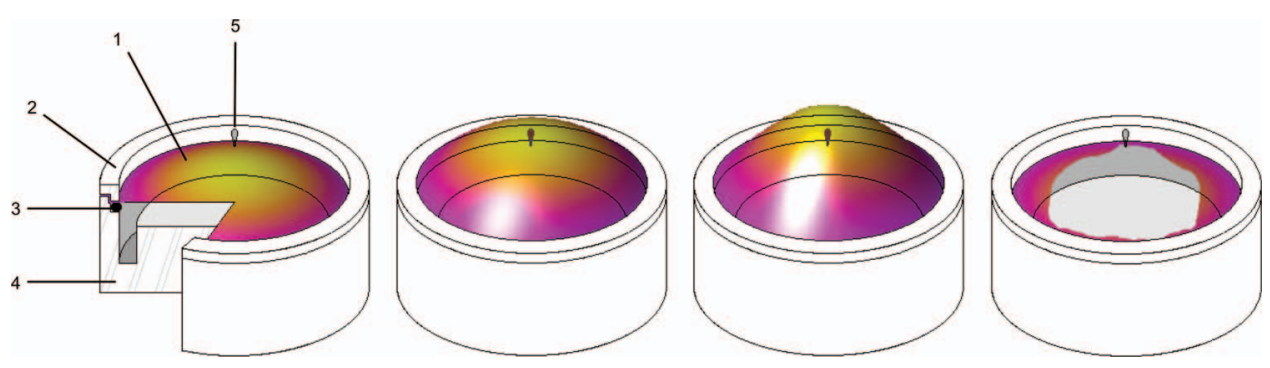

FIG. 1. (Color online) Cross-section of the airtight container, showing the membrane (1), the annular clamp (2), the O-ring (3), the body of the container (4), and the needle (5). For better visibility, the two side braces, which maintain the upper ring in compression over the membrane, are not shown on these schematics. The next views show the airtight container at various inflation stages during the evacuation of the vacuum chamber.

\section{B. Oxygen and water vapor permeation}

In order to protect samples for sufficiently long times inside the sealed container, the membrane material must have low gas permeation for oxygen and water vapor. The transport of these gases through polymer films is typically explained in terms of two concurrent mechanisms: (1) a bulk diffusive flow via a solubility-diffusion mechanism and (2) a flow through membrane defects (inhomogeneities, porosities, and microcracks). ${ }^{8}$ The solubility-diffusion mechanism consists of sequential steps where the permeants are absorbed onto the surface, dissolved into the material, transported by diffusion under the influence of the resulting concentration gradient and, finally, desorbed on the other side of the membrane. When one side of the membrane is first exposed to oxygen and water vapor, both flow rates and gas concentrations in the membrane vary with time. A certain permeation time is, however, needed for the first molecules of gas to reach the other side of the membrane. When bulk diffusive flow is predominant, this so-called "lag-time" $t_{0}$ can be approximated by ${ }^{9}$

$$
\mathrm{t}_{0}=\delta^{2} /(6 \mathrm{D}) \text {, }
$$

where $\delta$ is the membrane thickness and $\mathrm{D}$ is the gas diffusivity in the membrane material. The lag-time determines the maximum duration for transferring the sample safely in its container before any surface reaction starts with the permeants. In elastomers, oxygen and moisture diffusivities range typically between $\mathrm{D}=10^{-6}$ and $10^{-5} \mathrm{~cm}^{2} / \mathrm{s}$ (Ref. 10), which correspond to lag-times on the order of a few minutes for a
$0.5 \mathrm{~mm}$-thick membrane. Such lag-time values are long enough if the device is stored in a nitrogen-filled desiccator from the moment it is assembled in the glovebox to when it is finally exposed to air during its loading into the instrument vacuum chamber. It is important to note that, when assembling the device, the membrane must not be overly stretched, as this would not only increase the film stiffness and preclude proper inflation, but also greatly decrease the lag-time as a combined effect of thickness reduction and increased gas flow through membrane defects.

For times longer than the lag-time, both membrane diffusion and the kinetics of the chemical reaction between the gas and the reactive sample determine the flux of gas permeating inside the container. Assuming that a steady state is reached quickly, the flux $\mathbf{J}$, of gas through the membrane can be derived from Fick's first law,

$$
\mathrm{J}=\mathrm{D}\left(\mathrm{c}_{0}-\mathrm{c}\right) / \delta
$$

where $c_{0}$ and $\mathrm{c}$ are the permeant concentration on the upstream and the downstream side of the membrane, respectively. The concentrations may be replaced by the gas partial pressures, $\mathrm{p}_{0}$ and $\mathrm{p}$ on either side of the membrane, and Eq. (2) becomes

$$
\mathrm{J}=\mathrm{K}\left(p_{0}-\mathrm{p}\right) / \delta,
$$

with $\mathrm{K}$ the gas permeability coefficient. At low concentrations, gases solubility in polymers typically follows Henry's law and diffusion coefficients are pressure independent near
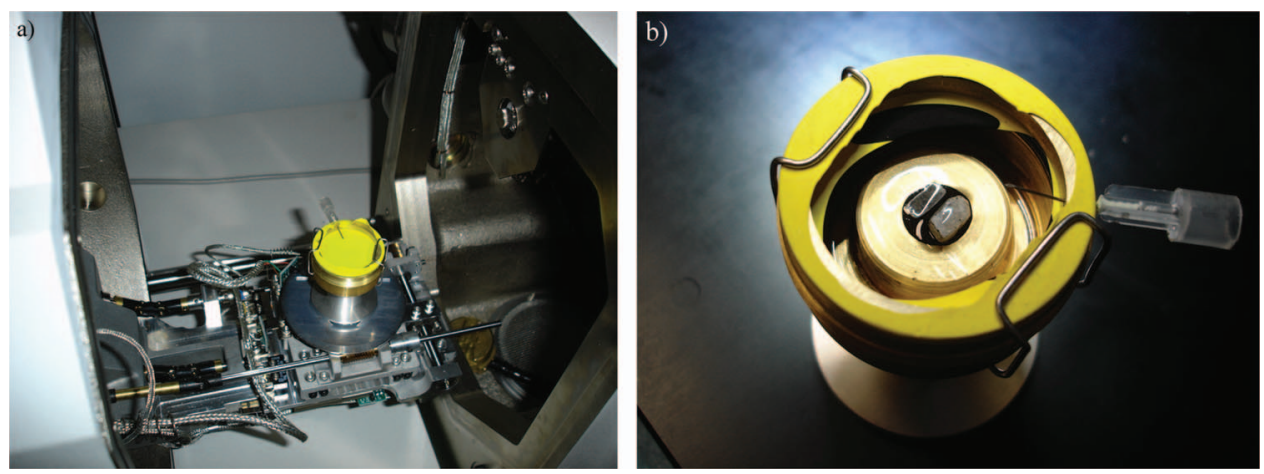

FIG. 2. (Color online) (a) General view of a sample loaded container installed in the chamber of a scanning electron microscope (Hitachi S-3400N VP-SEM). The puncturing needle is clearly visible above the yellow rubber membrane. (b) Container taken out of the microscope after analysis. Samples are glued on a piece of carbon tape in the center of the container. During the evacuation of the microscope chamber, the membrane ruptures and retracts towards the rim of the container, exposing the samples fully to the electron beam. After analysis, and quickly after opening the SEM specimen chamber, the samples are immersed in a drop of mineral oil for protection. 
TABLE I. Typical water vapor and oxygen permeation in various elastomer materials. ${ }^{9}$

\begin{tabular}{lcc}
\hline \hline & $\begin{array}{c}\mathrm{H}_{2} \mathrm{O} \text { vapor permeation } \\
\text { rate }\left(\mathrm{g} \mathrm{mm} / \mathrm{m}^{2} / \text { day }\right)\end{array}$ & $\begin{array}{c}\mathrm{O}_{2} \text { permeability coefficient } \\
\text { (std. cc mm/m } / \text { day/atm) }\end{array}$ \\
\hline Butyl rubber & 0.7 & 90 \\
Halogenated polyolefin & 1.2 & 270 \\
Nitrile rubber & $\ldots$ & 400 \\
Natural rubber & 1.8 & 1600 \\
Styrene butadiene & 2 & 1200 \\
Polyurethane & 2.5 & 2000 \\
Silicone & 3 & 3500 \\
\hline \hline
\end{tabular}

standard conditions. In those conditions, the permeability coefficient writes simply

$$
\mathrm{K}=\mathrm{DS}
$$

where $\mathrm{S}$ is the gas solubility coefficient in the membrane. For homogeneous membranes and permeants, such as oxygen, that do not strongly interact with the polymer, the permeability is a fundamental property of the membrane, independent of the polymer thickness. ${ }^{11}$ In the case of water vapor, however, the solubility strongly deviates from Henry's law and both diffusivity and permeability are concentration dependent and increase with water partial pressure. ${ }^{12}$ It has been observed that the rubber elastomers capable of large water uptakes have, in fact, relatively low diffusion coefficients and longer lag-times. ${ }^{13}$ Membranes which sorb little water behave according to Fick's law and the permeation rate is inversely proportional to film thickness. At high relative humidity, however, the permeability constant $\mathrm{K}$ varies with increasing thickness. ${ }^{14}$

From a polymer standpoint, gas solubility mostly depends on the mutual polarity between the gas and membrane molecules and similar polarities lead to higher gas solubility. ${ }^{15}$ Gas diffusivity, on the other hand, decreases with the size and mass of gas molecules and proceeds between the thermally activated voids that form and disappear within the polymer network. The mobility, the packing, and the cross-linkage of the polymer chains largely determine this phenomenon. ${ }^{8,15}$ As a consequence, elastomers, which are characterized by mobile chains, tend to have higher gas diffusion coefficients than other polymers and hence, shorter lag-times. To reduce the overall permeability of the membrane, butyl rubber, halogenated polyolefin rubbers with typical water vapor and oxygen permeability values below $1 \mathrm{~g} \mathrm{~mm} \mathrm{~m}^{-2} \mathrm{day}^{-1}$ and $100 \mathrm{~cm}^{3}$ (STP) $\mathrm{mm} \mathrm{m}^{-2}$ day $^{-1}$ $\mathrm{atm}^{-1}$, respectively, shall be preferred over natural rubber or silicone membranes (Table I). Other alternatives may consist of laminated or barrier coated elastomer films.

\section{APPLICATION EXAMPLE}

Various materials such as $\mathrm{Tl}^{+}: \mathrm{NaI}, \mathrm{Ce}^{3+}: \mathrm{LaBr}_{3}$, $\mathrm{Ce}^{3+}: \mathrm{LuI}_{3}$, and $\mathrm{Eu}^{2+}: \mathrm{SrI}_{2}$ are currently in use or being developed as scintillation detectors for high-energy physics experiments, medical imaging, non-destructive testing, nuclear surveillance or geological exploration. ${ }^{16-18}$ Unfortunately, these materials are sensitive to moisture and oxygen,
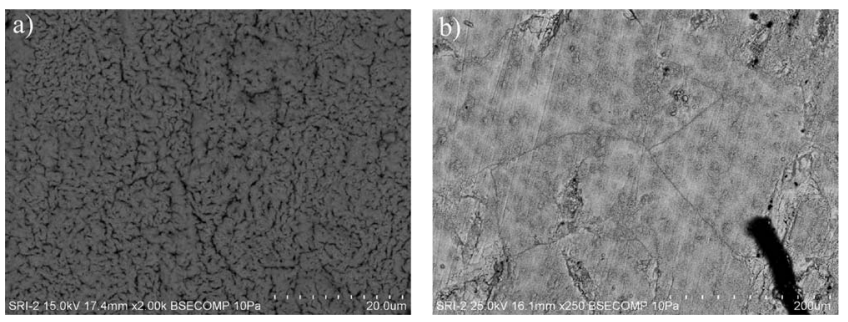

FIG. 3. (a) Electron micrograph of a polished $\mathrm{SrI}_{2}$ ceramic transferred without airtight container and exposed to ambient air for about $6 \mathrm{~s}$ during transfer from a dry $\mathrm{N}_{2}$ filled-desiccator to the VP-SEM chamber. (b) Surface of a polished ceramic sample transferred using an airtight container. The grainboundaries that define the ceramic microstructure are clearly visible. Localized precipitated residues forming grey patches on the surface of the sample are due to un-optimized etching conditions.

exposure to which can negatively affect their performance. Because the production and packaging of scintillators can generally be performed in an inert atmosphere, the hygroscopic or deliquescent nature of these materials is not a major impediment to their manufacture and use. The characterization of these materials using surface sensitive techniques such as electron microscopy or electron microprobe, however, demands special handling to preserve the samples surface after preparation. In the following example, we illustrate the use of an airtight container for visualizing the microstructure of $\mathrm{SrI}_{2}$ ceramics in a variable pressure scanning electron microscope (VP-SEM). A VP-SEM is a well-suited imaging instrument for this particular application as the chamber pressure can be controlled and gradually decreased, ${ }^{19}$ while observing the inflation and the rupture of the membrane (using an infrared chamber scope with the Hitachi VP-SEM, or a "TV signal" on other manufacturers). In addition, no further processing technique (e.g., sputter-coating for nonconductive samples) is required since the gas in the chamber allows image formation as well as charge stabilization for such electrically non-conductive samples. The samples under investigations were hot-pressed ceramics of Eu: $\mathrm{SrI}_{2}$ (see Ref. 20 for more details about their preparation), polished and etched at room temperature in a glovebox for $1 \mathrm{~min}$ in a 50:1 mixture of dry hexane and chloroform. These ceramic samples were carried in an airtight container equipped with a $500 \mu \mathrm{m}$-thick natural rubber membrane and transferred to the chamber of a VP-SEM within 2 min. Test samples, prepared under the same conditions, were simply carried in a dry $\mathrm{N}_{2}$ filled-desiccator and briefly exposed to air during their transfer to the VP-SEM chamber. After mounting the sealed container onto the microscope stage, the specimen chamber was partially evacuated, without raising the stage, i.e., maintaining a working distance of about $40 \mathrm{~mm}$ between the sample and the objective lens pole piece. In this way, the detectors and lenses were in no danger of being damaged by the inflating membrane. During evacuation, the inflating membrane was closely watched until punctured by the needle, when the membrane ruptured and retracted towards the rim of the container. At this point the stage was raised to a working distance of $5 \mathrm{~mm}$ and pressure lowered to $10 \mathrm{~Pa}$ for optimal resolution. An accelerating voltage from 15 to $25 \mathrm{kV}$ was applied for imaging of the exposed sample surface, using backscattered electron (BSE) detection. Figure 3 clearly 
shows that the airtight device effectively prevents hydration that otherwise completely alters the surface of the sample. Although experimental conditions can still be improved by using a better airtight membrane and optimized etching conditions for strontium iodide ceramics, grain boundaries as well as polishing grooves, are clearly visible on the protected sample (Figure 3(b)). Microstructure information revealed on such images can then further be used to elucidate the sintering mechanisms at work during the fabrication of this air-sensitive ceramic material. The present investigation additionally highlights a novel application of the variable pressure modality of scanning electron microscopy.

\section{ACKNOWLEDGMENTS}

This work was supported by the Domestic Nuclear Defense Office (DNDO) under Grant No. 2008-DN-077ARI005-02 and by the Defense Threat Reduction Agency under Grant No. HDTRA1-07-1-0009.

${ }^{1} \mathrm{~J}$. Goldstein, Scanning Electron Microscopy and X-Ray Microanalysis (Springer, New York, 2003).

${ }^{2}$ P. Echlin, Handbook of Sample Preparation for Scanning Electron Microscopy and X-Ray Microanalysis (Springer, New York, 2009).
${ }^{3}$ L. W. Hobbs, J. Phys. E: J. Sci. Instrum. 3, 85 (1970).

${ }^{4}$ C. Solliard and M. Rappaz, Rev. Sci. Instrum. 49(1), 101 (1978).

${ }^{5}$ C. T. Nguyen, T. Vu-Khanh, P. I. Dolez, and J. Lara, Int. J. Fract. 155, 75 (2009)

${ }^{6}$ C. T. Nguyen, T. Vu-Khanh, P. I. Dolez, and J. Lara, Int. J. Fract. 155, 83 (2009).

${ }^{7}$ Z. Zhou and B. Joos, Phys. Rev. B 56(6) 2997 (1997)

${ }^{8}$ S. C. George and S. Thomas, Prog. Polym. Sci. 26, 985 (2001).

${ }^{9}$ H. L. Frisch, J. Phys. Chem. 61(1), 93 (1957).

${ }^{10}$ L. K. Massey, Permeability Properties of Plastics and Elastomers (PDL Handbook, New York, 2003).

${ }^{11}$ A. S. Carpenter and D. F. Twiss, Rubber Chem. Technol. 13, 326 (1940).

${ }^{12}$ J. A. Barrie, D. Machin, and A. Nunn, Polymer 16, 811 (1975).

${ }^{13}$ H. Vromans and J. A. H. van Laarhoven, Int. J. Pharm. 79, 301 (1992)

${ }^{14}$ J. E. Ayer, D. R. Schmitt, and R. M. Mayfield, J. Appl. Polym. Sci. 3(7), 1 (1960).

${ }^{15}$ G. J. Van Amerongen, Rubber Chem. Technol. 24, 109 (1951).

${ }^{16}$ B. D. Milbrath, A. J. Peurrung, M. Bliss, and W. J. Weber, J. Mater. Res. 23(10), 2561 (2008).

${ }^{17}$ K. S. Shah, J. Glodo, M. Klugerman, W. Higgins, T. Gupta, P. Wong, W. W. Moses, S. E. Derenzo, M. J. Weber, and P. Dorenbos, IEEE Trans. Nucl. Sci. 51(5) 2302 (2004).

${ }^{18}$ N. J. Cherepy, G. Hull, A. D. Drobshoff, S. A. Payne, E. van Loef, C. M. Wilson, K. S. Shah, U. N. Roy, A. Burger, L. A. Boatner, W.-S. Choong, and W. W. Moses, Appl. Phys. Lett. 92, 083508 (2008).

${ }^{19}$ D. Stokes, Principles and Practice of Variable Pressure/Environmental Scanning Electron Microscopy (VP-ESEM) (Wiley, UK, 2008).

${ }^{20}$ S. R. Podowitz, R. M. Gaume, W. T. Hong, A. Laouar, and R. S. Feigelson, IEEE Trans. Nucl. Sci. 57(6), 3827 (2010). 